\title{
IDENTIFICACIÓN DEL VERDADERO ESTILO DE LEÓN PICARDO
}

\author{
POR \\ PILAR SILVA MAROTO \\ Universidad Complutense de Madrid \\ DAMIÁN LUENGO PEDRERA \\ Ldo. H. ${ }^{a}$ del Arte Univ. Autónoma de Madrid
}

\begin{abstract}
New documents have led to identify the altarpiece of Saint Bartholomew as Felipe Bigarny's and León Picardo's work of 1515 for San Esteban in Burgos. Sold to the church of San Lesmes in Burgos, has allowed us to study the style of León Picardo, his high quality and his dependence on flemish models. The catalogue of Picardo is drawn up, comprising works attributed to him or to his studio.
\end{abstract}

La localización del retablo de San Bartolomé que León Picardo y Felipe Bigarny llevaron a cabo desde el 22 de enero de 1515 para la iglesia de San Esteban de Burgos, mandado hacer por Francisco de Gumiel ${ }^{1}$ que, a la sazón, se encontraba en Roma, permite conocer sin ninguna duda el verdadero estilo del pintor. Este se asociaba hasta ahora con el que muestran las tres tablas procedentes de Santa Casilda -en la actualidad en la catedral de Burgos- en las que se representan el Calvario y dos escenas de la vida de San Vicente, titular de la iglesia en 1524 cuando Picardo contrató esta obra, estudiadas por Pilar Silva en 1994 con motivo de la exposición que se hizo con las obras flamencas y españolas de los siglos XV y xvı que se guardan en la sede burgalesa ${ }^{2}$.

Como ha sucedido en tantas ocasiones en la Historia del Arte, la aparición de un documento permite confirmar algo que intuían la mayor parte de los autores que se han referido a León Picardo. Estos, sólo aceptaban reconocer su mano en las tablas de Santa Casilda, como le sucedió a Angulo ${ }^{3}$, ya que su escasa calidad casaba mal con la fama con la que su autor había pasado a la posteridad. Se veía en él al interlocutor de Sagredo en Las Medidas del Romano (1526), al artista que supo conseguir la protección de los Condestables y que incluso trabajó fuera de Burgos para

1 Teófilo López Mata, El barrio y la iglesia de San Esteban de Burgos, 1946, pp. 106-108. Se recoge también en Pilar Silva Maroto Pintura hispanoflamenca castellana: Burgos y Palencia, Valladolid, 1990.III, p. 1033.

2 "La pintura española sobre tabla de los siglos xv y xvı en la catedral de Burgos", en La pintura sobre tabla de los siglos XV y XVI de la catedral de Burgos, Libro-Catálogo, Burgos 1994, pp. 175-191 y 205-207. Se incluye en ella la bibliografía de esta obra, dada a conocer como de León Picardo en 1939 por Luciano Huidobro en "Artistas burgaleses. León Picardo pintor y escultor", Boletín de la Comisión de Monumentos Histórico Artísticos de Burgos, 1939, pp. 188-194.

3 «León Picardo", Archivo Español de Arte, 1945, pp. 84-96. 
para comitentes tan importantes como el cardenal Cisneros, como se ha sabido recientemente gracias a las investigaciones de Miguel Ángel Castillo Oreja ${ }^{4}$

La identificación de este retablo realizado conjuntamente por Bigarny y Picardo en 1515 no ha sido fácil, ya que se daba por perdido desde que López Mata publicó en 1946 el documento que atestiguaba su ejecución en su monografía de la iglesia de San Esteban de Burgos. Sin duda se juzgó que él había consultado toda la documentación del templo y que no había encontrado nada en ella relativo al momento y las circunstancias en que fue retirado del lugar para el que se llevó a cabo. Nada podía hacer pensar entonces que las cuatro tablas con la historia de San Bartolomé que Picardo ejecutó para San Esteban eran las mismas que se encontraban en la iglesia de San Lesmes de Burgos. En este último templo se tenía noticia de que las tablas se encontraban allí, al menos desde el siglo XIX en que se refiere a ellas Antonio Buitrago Romero en su Guía general de Burgos ${ }^{5}$. Al separarse las pinturas de los relieves dedicados a San Bartolomé y el resto de los elementos de talla que se conservan del retablo, resultaba lógico que nadie las asociara con las de San Esteban. Hasta 1946 no se supo que Bigarny y Picardo habían hecho un retablo de esa advocación para ese templo burgalés; y para entonces ya se creía conocer el estilo de León Picardo, desde que en 1939 Huidobro identificara las tablas que este pintor contrató en 1524 para San Vicente de los Lagos con las que conservaba la catedral de Burgos procedentes de Santa Casilda 6 . Sólo así se explica que, antes de que esto sucediera, en 1933, Gómez Moreno, al referirse al retablo mayor de la catedral de Oviedo ${ }^{7}$, en una de esas intuiciones geniales, señalaba cómo el estilo de Picardo «quisieramos descubrirle en las tablas de la Historia de San Bartolomé que hay en San Lesmes de Burgos, tan clásicas y bellas, mas falta asidero». Sin duda, esa falta de asidero, y en mayor medida aún, la identificación de las tablas de San Vicente, eliminaron el nombre de Picardo entre los posibles autores. Prueba de ello es que en 1942 Post asociaba las cuatro pinturas de la historia de San Bartolomé existentes en San Lesmes de Burgos con Jan Joest de Calcar ${ }^{8}$. Este era el autor del políptico del trascoro de Palencia, contratado en 1505 -supuestamente en Bruselas-, por el obispo palentino Juan de Fonseca que ese año se encontraba en los Países Bajos, con quien, en nuestra opinión, nada tiene que ver el estilo de las tablas de San Lesmes.

En 1993 Damián Luengo estuvo en la iglesia de San Lesmes de Burgos y, al conocer las tablas de San Bartolomé, sugestionado por su calidad decidió investigar los datos que se conocían sobre ellas. Al comunicarle el párroco que el retablo en el que se encontraban se había formado recientemente con los restos de otro de escultura, hecho también en el XVI que se conservaba en San Lesmes (fig. 1), se dio cuenta de que tanto las tablas como las tallas -dedicadas ambas a San Bartolomé- eran de la misma época. Al comprobar que no se repetía ninguna escena y, sobre todo, que las dimensiones de las pinturas coincidían con los huecos de las calles laterales del cuerpo del retablo de escultura, supuso que todas ellas pertenecían a la misma obra. Comoquiera que conocía el documento relativo al retablo de San Bartolomé que Bigarny y Picardo hicieron para San Esteban, se planteó la hipótesis de si podía tratarse del mismo. Para ello se basaba

\footnotetext{
4 Se refiere a ello por vez primera en "La eclosión del Renacimiento: Madrid entre la tradición y la modernidad" en Madrid en el Renacimiento, Madrid, 1986, pp. 136-169. De forma más amplia lo aborda después en "La selección del encargo: Felipe Bigarny en las empresas artísticas de Cisneros", en Tiempo y espacio en el arte. Homenaje al profesor Antonio Bonet Correa, Madrid, ed. Complutense, 1994, t. II, pp. 789-807.

5 1876, p. 206. Alude allí a su brillante colorido.

6 Art. cit, 1939, pp. 188-194. En 1524 la iglesia se encontraba bajo la advocación de San Vicente, cambiándose después por la de Santa Casilda por la devoción que gozaba esta santa. Una vez conocido esto, no resulta extraño que el retablo estuviera dedicado al que era el santo titular entonces. Lo componían tres tablas que representaban a San Vicente en el ecúleo, el cadáver del santo guardado por el cuervo y la Crucifixión.

7 "El retablo mayor de la catedral de Oviedo", Archivo español de Arte y Arqueología, 1933, pp. 5-6.

8 "A second retable by Jan Joest in Spain, Gazette des Beaux Arts, 1942 (II), pp. 127-134.
} 
en el hecho de que el donante, un clérigo, estaba protegido por San Francisco al que seguía San Esteban (fig. 2), perfectamente identificado al ir vestido como diácono y exhibir su atributo, las piedras que sostiene con su túnica. En su opinión, el clérigo podía ser Francisco de Gumiel con su patrono San Francisco. El que junto a éste se hubiera representado a San Esteban se justificaría si respondiera al homenaje que el posible comitente, Gumiel, otorgaba al patrón del templo para el que esta obra se destinaba. Aunque él no tenía ya dudas, sobre que se trataba del mismo retablo que se hizo para la iglesia de San Esteban, lo difícil era probarlo. No obstante, por esta vez, la suerte no fue esquiva. La lectura del Viaje de España de Ponz le dio una nueva pista. Al describir el interior de la iglesia de San Lesmes en 1778, este autor señalaba cómo « en el retablo de Santa Catalina hay diez estatuas y tres bajorrelieves que deben apreciarse, como también cuatro pinturas como del estilo de Lucas de Holanda» 9 .

Pese a que no se mencionaba la advocación de San Bartolomé -y de la lectura de este texto no se podría deducir otra cosa que sus tablas y relieves estaban dedicados a Santa Catalina-, al ser cuatro sus tablas y tres sus relieves no le fue difícil llegar a la conclusión -o mejor aún confió en- que se trataran de las mismas que con la advocación de San Bartolomé han llegado hasta nuestros días. Mientras esto se confirmaba o no, lo cierto es que la cita de Ponz aportaba un dato que al final habría de resultar definitivo. En él se mencionaba que se trataba del retablo de Santa Catalina, esto es, el que había pertenecido a la cofradía de Santa Catalina que durante mucho tiempo había existido en la iglesia de San Lesmes. Al comunicar Damián Luengo el resultado de sus investigaciones al actual párroco del templo, don César Alonso de Porres, éste le informó sobre la existencia en el archivo de la parroquia de los documentos pertenecientes a dicha cofradía que, con todos sus bienes, pasaron a San Lesmes en 1776. Don César quedó encargado de revisar su archivo y, muy pronto, encontró un dato que demostraba que la cofradía de Santa Catalina -con sede en la parroquia de San Lesmes- había comprado un retablo a la fábrica parroquial de San Esteban en el año 1705 por $13.600 \mathrm{mrs}^{10}$. Pese a que en esta cita no se mencionaba la advocación del retablo, lo que quedaba por confirmar era ya muy fácil. El párroco de San Lesmes sólo tuvo que acudir a mirar en la documentación de San Esteban las cuentas del año 1705. Por fortuna, en ella se conservaba aún registrado el dato que corroboraba todo lo que Damián Luengo había supuesto. En el libro de fábrica correspondiente a los años de 1621 a $1729^{11}$ se recoge la partida de 13.600 mrs que se obtienen por la venta del retablo de San Bartolomé a la cofradía de Santa Catalina, siendo mayordomo José de Porres. No existían ya más dudas, sólo la constatación de que un retablo de la advocación de San Bartolomé -como en otros muchos ejemplos de la época ${ }^{12}$, , se había adquirido como marco para la estatua de Santa Catalina que poseía la cofradía dicha advocación en San Lesmes.

En este estadio de la investigación se solicitó la colaboración de Pilar Silva Maroto para que fuera a Burgos, estudiara las tablas y comprobara su conexión con otras de la zona con el fin de hacer una publicación conjunta. Al retrasarse el proceso de realización del trabajo, el párroco de San Lesmes optó por publicar él solo los datos correspondientes a la historia material del reta-

9 XII, Carta IV, 17. Generalmente Ponz las consideraba de Lucas de Holanda cuando se trataba de obras flamencas o de gran calidad. Por ejemplo, en Burgos juzga de ese pintor las tablas del retablo del Bautista de la Cartuja de Miraflores hechas por Juan de Flandes, según se sabe desde que Josef de Coo y Nicole Reynaud lo dieron a conocer en 1979. Sobre esto, veáse "Origen del retablo de San Juan Bautista atribuido a Juan de Flandes», Archivo Español de Arte, 1979, pp. 125-144.

10 A. Parroquia de San Lesmes de Burgos. Libro de Cuentas de la cofradía de Santa Catalina, 1570-1735, f. 348.

11 A. Parroquia San Esteban de Burgos. En depósito en el A. Diocesano de Burgos. Libro de Fábrica de 1621-1729, fol. $259 \mathrm{v}^{\mathrm{o}}$

12 Sucedió también con el retablo del Cristo del Monasterio de Oña que se trasladó a una de sus dependencias, la ermita de San Nicolás de Espinosa de los Monteros (Burgos), sustituyéndose en ella la imagen de Cristo en la Crucifixión por la del titular San Nicolás. Sobre esto veáse Pilar Silva Maroto, ob. cit., 1990, III, pp. 867-868. 
blo, así como otros relativos a su restauración por el taller Ikonos de Burgos, a los que nos remitimos ${ }^{13}$. No aborda, en cambio, don César ninguna de las cuestiones relativas a la intervención de Bigarny y de León Picardo en el retablo, precisamente lo que va a constituir en parte el objetivo de este trabajo, que se va a centrar en la figura del pintor picardo. Pese a ello, no queremos dejar de aludir a las esculturas salidas del taller de Bigarny, ya que, al conocerse su estilo, es obligado el confirmar la participación de su taller, porque, de ese modo, resulta más convincente aún si cabe la constatación de que las cuatro tablas con las escenas de la historia de San Bartolomé corrieran a cargo de León Picardo.

$\mathrm{Al}$ analizar nosotros las piezas de talla y compararlas con otras que el borgoñón ejecutó en los años anteriores a la realización del retablo de San Bartolomé para San Esteban de Burgos, pudimos comprobar los puntos en común que tiene con otras obras realizadas personalmente por él y por su taller ${ }^{14}$. Este último debió intervenir de algún modo en la ejecución de este conjunto como lo prueba el que, en las diferencias que surgen con la fábrica de San Esteban de Burgos -que se encarga de pagar las obras-, se menciona junto a Bigarny y Picardo a Juan de Chombreros (?) ${ }^{15}$. Probablemente se trata del mismo escultor, vecino de Burgos, Juan de Cobrijos o Cabrejos que se encargó de llevar a Palencia, en diciembre de 1506 y marzo de $1507^{16}$, las tallas realizadas por Bigarny para el retablo mayor de su catedral. Aunque consta en ocasiones que Bigarny está obligado a realizar él mismo las obras, porque así se lo exigen los comitentes, nada sabemos respecto a las condiciones en que se contrató el retablo de San Bartolomé. La única vía que queda para comprobar si participó en ellas es comparar sus tallas con otras en las que se comprometió mediante contrato a hacerlas él mismo, como sucede con los relieves del trasaltar de la catedral de Burgos, iniciados en 1498 a su llegada a la ciudad, el retablo de la capilla de la Universidad de Salamanca que efectúa entre 1504 y 1505 o las historias de la calle central del retablo de la catedral de Palencia, concluido en 1509, a falta de los retablos perdidos de Alcalá de Henares y de Torrelaguna.

Pese a que, como hemos indicado antes, no es nuestra intención hacer un análisis pormenorizado de la talla del retablo de San Bartolomé contratado por Bigarny para San Esteban -que confiamos emprenda pronto alguno de los especialistas en escultura de comienzos del xvI-, no por ello queremos dejar de señalar algunos de los puntos de contacto entre ellas y las que realizó Bigarny personalmente, sin que esto implique que se deban exclusivamente a su mano. Por ejemplo alguno de los apóstoles, como el que por sus rasgos podría identificarse con San Pedro, muestra los plegados que tanto repite el borgoñón; y lo mismo sucede con los que forma la indumentaria del donante arrodillado, rotos sobre el plano de base, ocupando gran parte del espacio disponible, que se asemejan a los de los Reyes Católicos de la capilla real de Granada, posteriores a éstos, o los de la dalmática de San Esteban, situado a la izquierda de ese mismo relieve (fig. 2). Y también coinciden algunos de sus tipos humanos con los de otras obras en las que consta la intervención del escultor. Se puede constatar en el personaje barbado y ricamente vestido, identificado por el bastón que porta con el responsable del martirio de San Bartolomé en los dos relieves en que Bigarny representa este pasaje de la historia del apóstol (fig. 3), muy similar al que

13 César Alonso de Porres Fernández, “Identificación de un retablo de Vigarny y Picardo que se daba por desaparecido", Boletín de la Institución Fernán González, 1995/2, pp. 363-364.

14 En este punto agradecemos la ayuda que nos ha prestado Miguel Ángel Castillo Oreja que, tras ver las reproducciones de las piezas de talla conservadas, opinó que podrían haber salido del taller de Bigarny. Y también fueron de gran ayuda las sugerencias que nos proporcionó María Ángeles Toajas Roger sobre los motivos decorativos empleados tanto por Bigarny como por Picardo. Respecto a Bigarny, aún no se ha llevado a cabo una monografía sobre él, aunque sus obras se han estudiado independientemente en distintos libros y artículos. En abril de 1996, después de.redactarse este artículo, Isabel del Río de la Hoz ha presentado su tesis doctoral sobre Felipe Bigarny, en la Universidad Complutense.

15 López Mata, ob. cit., 1946, p. 107.

16 Sobre esto véase Francisco Portela Sandoval, La escultura del Renacimiento en Palencia, 1977, pp. 46 y ss. 

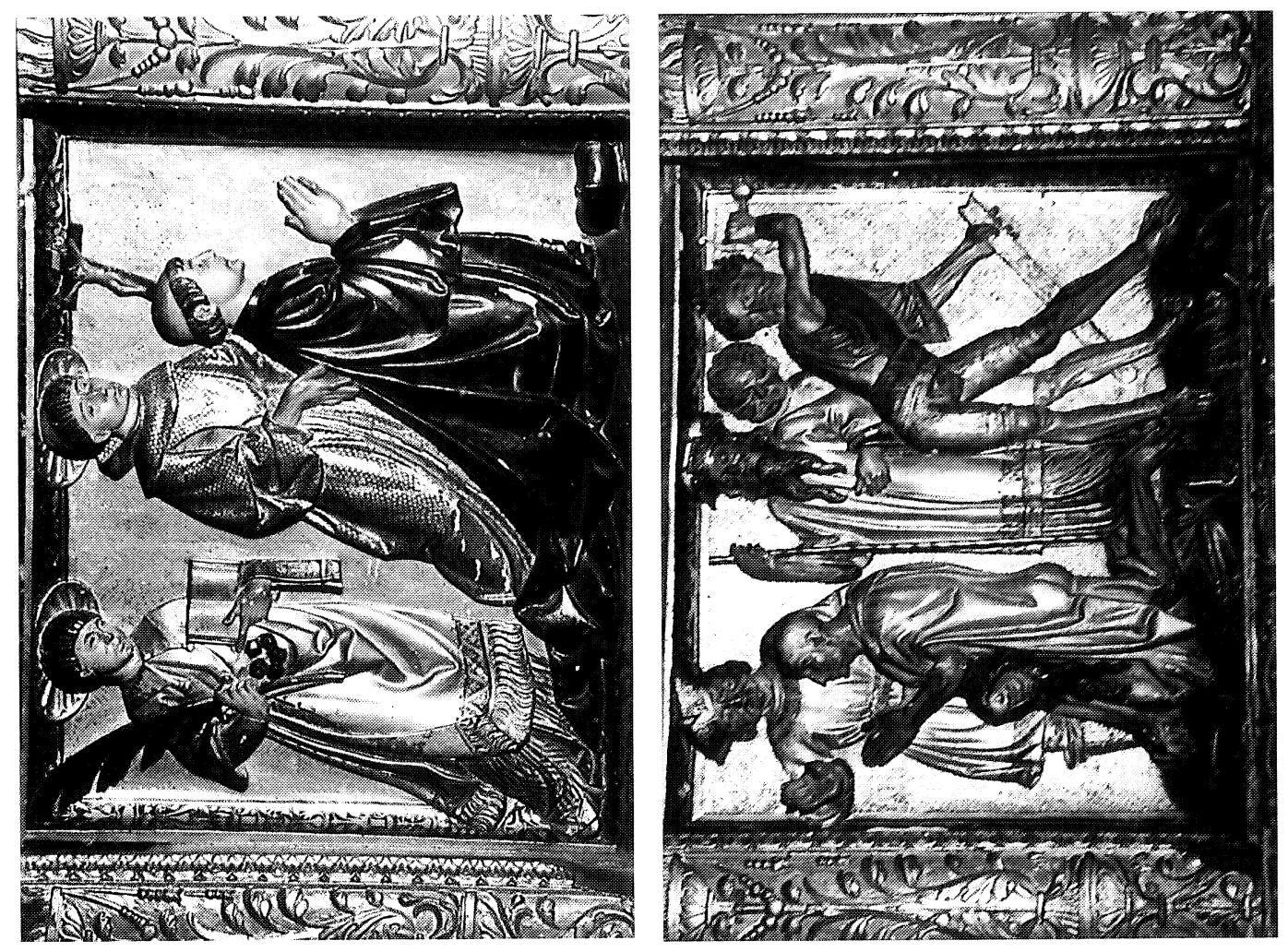
utiliza el borgoñón para el San Jerónimo del retablo de la capilla de la Universidad de Salamanca, reproducido por Gómez Moreno en su Catalogo Monumental de Salamanca.

Centrándonos en las pinturas, objeto de nuestra investigación, para nosotros no existen dudas de que en ellas se puede reconocer el verdadero estilo de León Picardo. Como ya apuntó Pilar Silva al referirse a este maestro en dos ocasiones en 1994 y 1995 17, aunque Picardo también contratase el retablo de la iglesia de San Vicente de los Lagos en 1524, pudo no haber intervenido personalmente en él, si no se le exigió así mediante contrato. En ese caso, el pintor pudo haber requerido la participación de alguno de sus colaboradores - que no miembro del taller-, ya que el estilo que muestran sus tres tablas nada tiene que ver con el que ostentan las de la historia de San Bartolomé ${ }^{18}$. Pese a que somos conscientes de que, respecto al retablo de San Bartolomé, se podían utilizar argumentos similares, para nosotros resulta mucho más improbable que en el caso anterior el que Picardo cediese su ejecución a un colaborador. Para confirmarlo no existe prueba mayor que la calidad objetiva de las pinturas de San Lesmes que se deben a la mano de un pintor conocedor directo del arte nórdico, como sin duda lo fue Picardo -lo que no se puede asegurar, sino más bien lo contrario, del que hizo las de San Vicente ${ }^{19}-$. Junto a este argumento -decisivo en nuestra opinión- se pueden señalar otros, como el que el retablo se hiciese al poco tiempo de llegar Picardo a Burgos y para una iglesia importante de la ciudad, donde muchos podrían contemplarla, en colaboración con el más afamado escultor burgalés y para un comitente relevante, Francisco de Gumiel, notario apostólico, que, cuando manda hacer la obra en 1514, se encontraba en Roma al servicio del papa León X.

Como ya señaló López Mata en $1946{ }^{20}$, a principios del siglo xvı el rico mercader Pedro López de Gumiel, parroquiano de San Esteban, tuvo una gran devoción por San Bartolomé, igual que sus descendientes. Aunque en esa iglesia existía un altar dedicado al apóstol con un retablo antiguo, los Gumiel siguieron promoviendo su devoción. Así, en 1490, Alfonso López de Gumiel y su esposa obtuvieron del cardenal de San Jorge el reconocimiento de festividades e indulgencias para el altar de San Bartolomé y, con la autorización del papa Inocencio VIII, se ordenaba el envío de reliquias desde el monasterio de San Anastasio de Roma a la iglesia burgalesa de San Esteban para contribuir a la exaltación de su culto ${ }^{21}$. Años más tarde, en 1514, una bula del papa León X otorgaba y confirmaba perdones, gracias e indulgencia a los que visitaran el altar del apóstol en San Esteban. Aludía asimismo en ella al predilecto maestro Francisco de Gumiel, clérigo burgalés, notario apostólico, escritor y familiar del Santo Padre, así como a la devoción de la familia Gumiel hacia el santo mártir, bajo cuya advocación había construido el retablo que existía entonces ${ }^{22}$.

17 Véase nota 2 y Pilar Silva Maroto. "La pintura en Alcalá de Henares en la época de Cisneros: Notas para su estudio" en La Universidad Complutense y las Artes, VII Centenario de la U. Complutense. Congreso celebrado en la Facultad de Geografía e Historia (30 nov.-1-3 dic. 1993), Madrid, 1995, p. 96. Cuando se redactaron estos dos textos la autora conocía ya el documento sobre el retablo de San Bartolomé, pero se limitó simplemente a mencionar el hecho de la aparición de los nuevos datos por no interferir la marcha del trabajo conjunto que se estaba realizando.

18 Incluso pudo haber cedido su ejecución a otro pintor mediante traspaso de contrato. En ese caso, si no se conoce la existencia del nuevo documento, erroneámente se puede llegar a deducir que el que lo llevó a término fue el que se encargó de él en primer lugar. Por lo que respecta al retablo de San Vicente, consideramos que, entre las dos opciones, resulta mucho más probable que se diese a un colaborador del taller, al tratarse de una obra de carácter local.

19 En el texto citado en la nota 2 se reproducen las tres tablas que lo componen (nota 6) y se incluye un análisis de las características estilísticas del que antes se juzgaba el estilo de León Picardo, definido por primera vez por Angulo (art. cit., 1945, pp. 84 y ss.). Se detecta en él una dependencia de Gossaert y de van Orley, acorde por tanto a una tradición distinta a la que muestran las tablas de San Bartolomé de San Lesmes. Prueba de ello es que sus figuras muestran unas formas más amplias, de tradición cinquecentista, llenando todo el espacio disponible, ayudadas también por los vestidos que se rompen en pliegues desordenados que denotan su deuda con el estilo de Gossaert.

20 Ob. cit., 1946, pp. 106-110.

21 López Mata, ibid., p. 106, A. Parroquia de San Esteban, pergamino.

22 Idem, Bula, papel. 
Sin duda, la Bula papal fue la causa determinante de que se decidiera sustituir el viejo retablo por uno nuevo. El promotor fue Francisco de Gumiel que, según señala López Mata, mandó enviar la traza desde Burgos a Roma para su aprobación ${ }^{23}$. Pese a que no parece haber dudas sobre el papel que tuvo Gumiel, como lo prueba su presencia en el banco del retablo, protegido por San Francisco en el relieve salido del taller de Bigarny (fig. 2), lo cierto es que fue el mayordomo de la iglesia de San Esteban el encargado de pagar a los artistas y de hacer frente al pleito que se suscitó. Y quién sabe si hasta fue él quién sugirió los nombres de Bigarny y de Picardo, aun cuando, en este caso, la elección no debió plantear dificultades. Prueba de ello es que el borgoñón era el mejor escultor de la ciudad, requerido para trabajar en la catedral de Toledo y en otros lugares de Castilla y Picardo debía haber incrementado su fama desde que intervino en los retablos que hizo en unión de Bigarny para el Cardenal Cisneros en la Magistral de Alcalá de Henares y en el convento de la Madre de Dios en Torrelaguna entre 1509 y 151324 .

Gracias a la documentación conservada en San Esteban, publicada por López Mata en 1946 se sabe que el 22 de enero de $1512^{25}$ "yo el dicho Leon picardo haga de pintura el Retablo que el dicho maestre filipe ha de hacer de tabla de la muestra que esta firmada de mi el dicho escribano en que ha de aver quatro estorias de pincel de la estoria del señor San Bartolomé e todo lo otro estofado e dorado testigos leon picardo pintor e Bernardino de Valmaseda su criado ...». En octubre de 1515 el mayordomo registra unos pagos a Bigarny y a Picardo, a quien entrega $20.000 \mathrm{mrs}{ }^{26}$. Surgido un pleito entre los artífices y el mayordomo de la iglesia, éste nombra como árbitros a Francisco de Colonia y al pintor Alonso de Sedano el 2 de septiembre de 1516. Estos mandan completar algunas cosas relativas a la talla y a su pintura y dorado y tasan la labor de Bigarny en $55.000 \mathrm{mrs}$ y la de Picardo en 45.000 27. El 6 de junio de 1520 , Nicolás de Vergara confirma que Bigarny cumplió la sentencia que le impusieron Colonia y Sedano ${ }^{28}$ y, dos días después, el borgoñón se daba por contento y pagado de lo que se le debía. Un año antes, el retablo ya estaba acabado, registrándose en las cuentas correspondientes a esa anualidad las cantidades que se satisfacen a los artífices, $6.512 \mathrm{mrs}$. para Bigarny y 27.625 para Picardo ${ }^{29}$, quien debió acabar las tablas de la historia del santo antes de que surgiese el pleito en septiembre de 1516 .

\section{Las cuatro tablas de la vida de San Bartolomé de San Lesmes de Burgos y el verdadero estilo de León Picardo}

Como ya indicara Post en 1942 al analizar las cuatro pinturas que él juzgaba de la mano de Jan Joest de Calcar, el comitente ha seleccionado dos temas que pertenecen a la leyenda demoníaca de la historia del apóstol, muy rara en otros países, pero de la que se conservan algunos ejemplos en España ${ }^{30}$. Entre las fuentes que se conocen de ella, Guy de Tervarent y Baudoin de

\footnotetext{
23 Idem.

24 Véase nota 4.

25 López Mata, ob. cit., pp. 106-107. A. Parroquia de San Esteban, Legajo de papeles inútiles.

26 Ib., p. 107. A. Parroquia de San Esteban, Libro de Fábrica, fol. 289.

27 Ib., pp. 107-108, A. Parroquia de San Esteban, papeles inútiles. Recog. P. Silva Maroto, ob. cit., 1990, III, pp. 1033.

28 Ib., p. 108, A. Parroquia de San Esteban, papeles inútiles.

29 Ib., pp. 108-110, A. Parroquial de San Esteban, Libro de Fábrica, fol. 137.

30 Post, art. cit. 1942, pp. 127 y ss.. Uno de ellos, bastante anterior, es el retablo de la catedral de Tarragona, obra de Juan Tarragona, que estudian José Gudiol y Santiago Alcolea en Pintura gótica catalana, Barcelona, ed. Polígrafa, 1986, p. 65 , cat. 155 , láms. 301-303.
} 
Gaiffier se refieren en su artículo, «el diablo ladrón de niños» 31, al manuscrito 1.116 de la Biblioteca Real de Bruselas, escrito en flamenco, en el que se trata ampliamente el rapto de San Bartolomé. Alude el texto a una pareja de origen real que vivía en Siria y estaba desolada por ser estéril. Tan grande era su pena que el hombre prometió al Dios de Israel entregarle para su servicio al fruto de sus entrañas. Cuando su mujer concibió un hijo, durante el embarazo presintió que éste tendría un poder sobre los diablos. Al nacer el niño y comprender Satán que era un terrible enemigo, se hizo aconsejar por otros demonios. Uno de ellos le dijo que había que raptarle y llevarle a la cima de una montaña, tirándole en la nieve para que muriera de frío. Sin duda, el tema que se relata en la primera escena está conectado con este pasaje. Se trata del rapto de San Bartolomé recién nacido por Satán y su sustitución por un demonio (fig. 4). El segundo episodio aparece también relatado en el manuscrito flamenco. De acuerdo con este texto, mientras los padres se daban cuenta de la sustitución, un sacerdote judío, que atravesaba las montañas, escuchó unos gemidos, mandando a sus servidores que fueran al lugar de donde procedían los gritos y trajeran al niño, si lo encontraban, localizándole aquéllos en la nieve. Aunque no hay nieve en la tabla de Picardo, en ella se puede reconocer fácilmente al sacerdote (fig. 5), representado como un obispo, como era habitual en la época, y a sus servidores a los que encomienda buscar al niño, visible en lo alto, junto a un animal, que nada tiene que ver con la cierva que citaba Post en 1942.

Las otras dos tablas dispuestas en el cuerpo inferior reproducen dos episodios más conocidos de la vida de San Bartolomé al que León Picardo traduce con el manto blanco, acorde con la descripción de La Leyenda Dorada de Voragine. En la de la izquierda, representa al santo en el templo del dios pagano Astaroth, cuya estatua se quiebra cuando Bartolomé libera a un hombre poseído (fig. 6). En la de la derecha, Bartolomé exorcisa a la hija del rey Polemio de la India en primer plano (fig. 7). Al fondo dispone otras tres escenas secundarias conectadas con este suceso. A la izquierda, en un escenario urbano, se incluye el llamamiento que se le hace para que realice el exorcismo. En el centro aparece rechazando los camellos cargados de riquezas que el rey le otorga como recompensa, mientras que, a la derecha, traduce al apóstol apareciéndose al rey acostado en su lecho al día siguente del milagro.

Estas cuatro tablas propiedad de la iglesia burgalesa de San Lesmes, dedicadas a la historia de San Bartolomé, constituyen el punto de partida para reconstruir la verdadera personalidad artística de León Picardo. Al tratarse de una obra de calidad y de técnica muy cuidada y corresponder a una etapa temprana de la producción del pintor que, cuando la ejecutó, llevaba sólo seis años en Burgos, el análisis de las caracteristicas que muestra su estilo resulta decisivo para intentar comprender en qué medio pudo transcurrir su formación, ya que no se conserva ningún dato sobre ella. Una vez completado, la conclusión a la que puede llegarse es que, aunque el apellido con el que se le conoció en España alude a su origen en la región francesa de la Picardía, lo que se percibe en su estilo es la fuerte deuda contraida con la pintura flamenca. Esto último aboga, en nuestra opinión, por que lo más seguro es que su formación se completara en los Países Bajos. Pese a que el estilo de Picardo no muestra una dependencia tan fuerte con el de ninguno de los pintores flamencos u holandeses conocidos que permita vincularle directamente con él, lo cierto es que existen algunas notas que le conectan con el arte brujense de los últimos años del xv y los primeros del XVI, precisamente el momento, en que se puede situar el fin del aprendizaje de Picardo, si se tiene en cuenta que ya estaba en Burgos en 1509.

Entre los que trabajaban entonces en Brujas se encontraba Jan Provost. Este último pintor, originario de Mons en el Hainaut, próximo a Valenciennes, donde desarrollaba su labor Simon

31 "Le diable, voleur d'enfants», Homenaje a Antonio Rubió i Lluch. Miscellania d'estudis Literaris, histories i lingüistics, vol. II, 1936, pp. 33 y ss. 

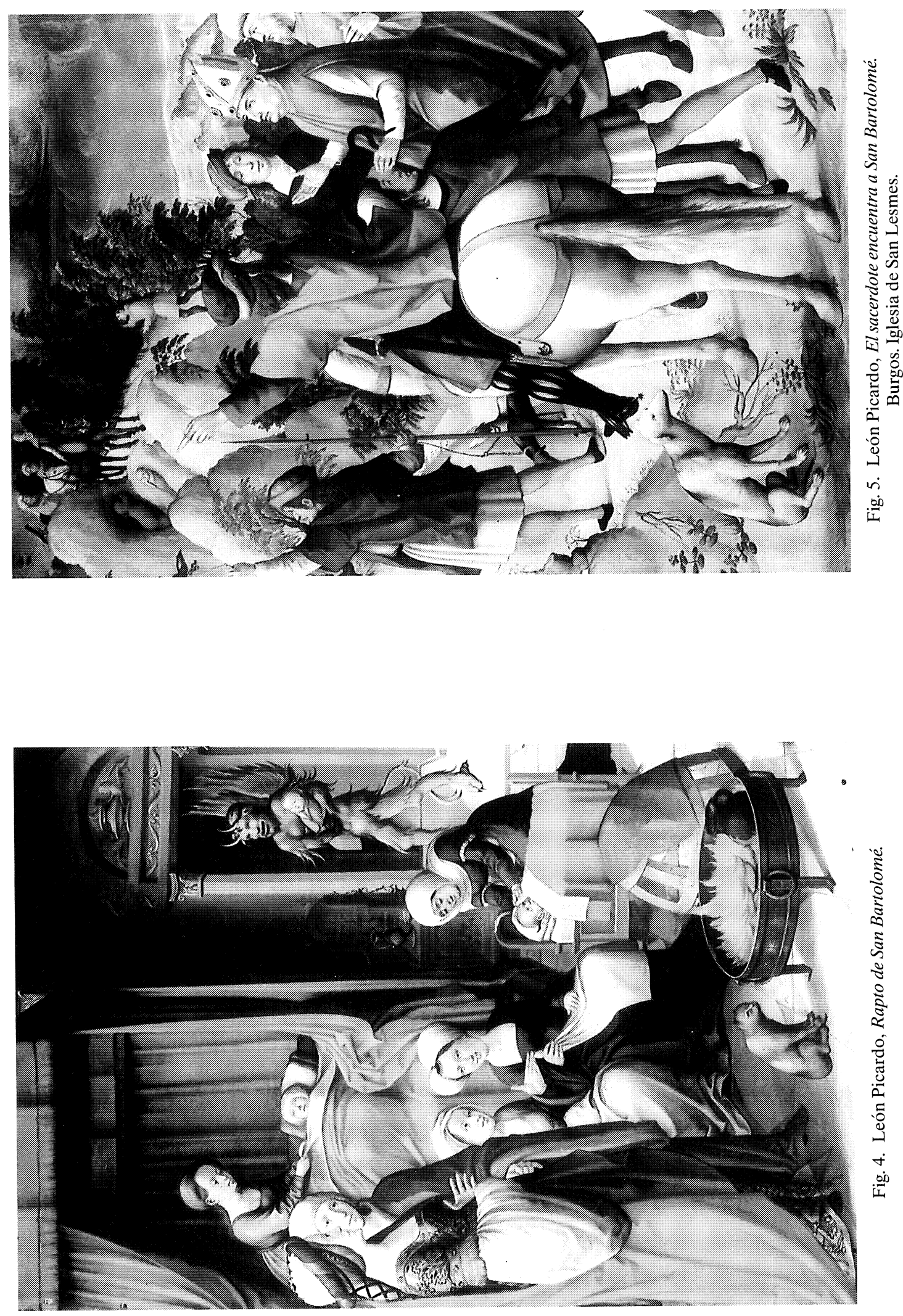

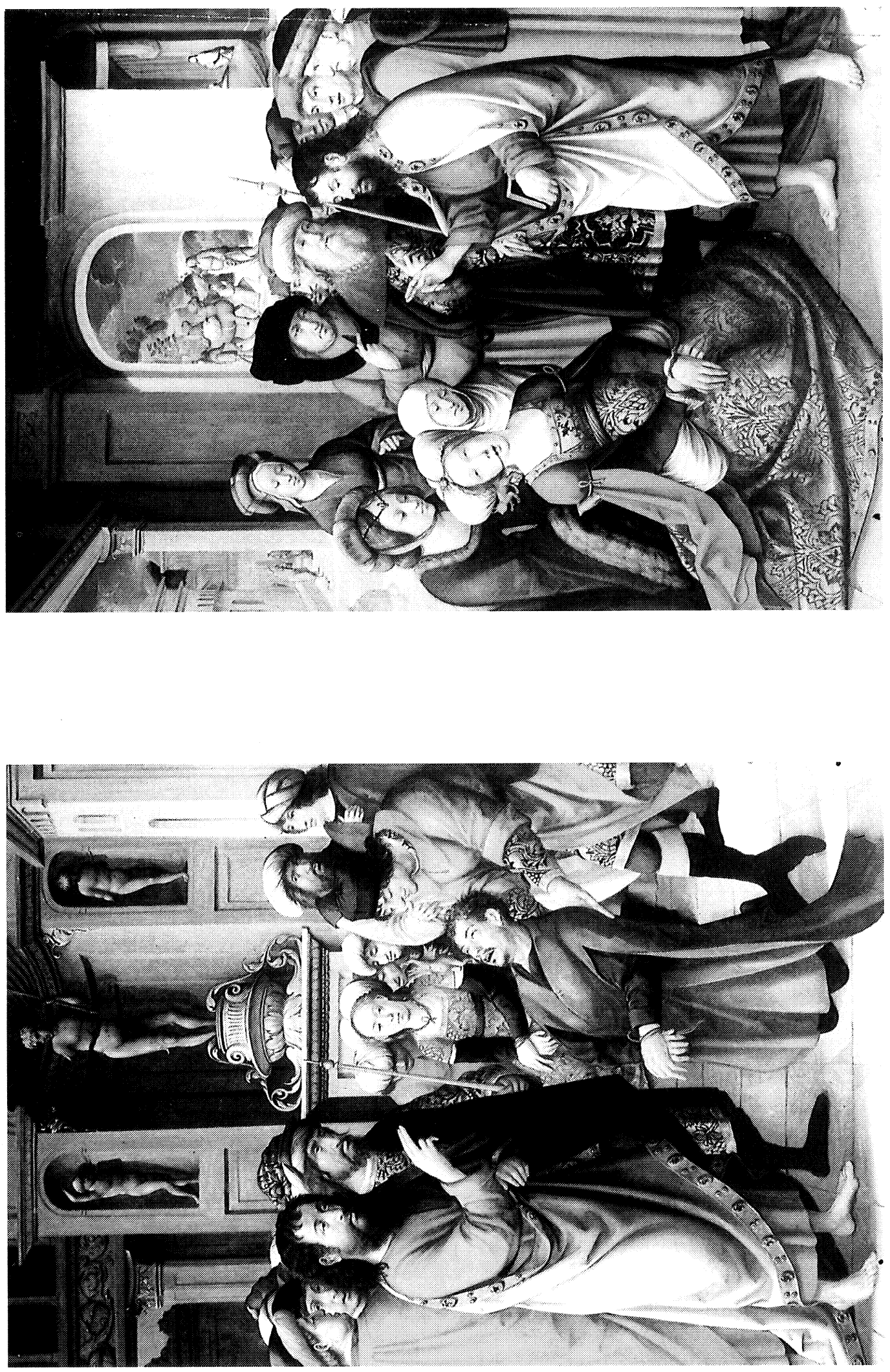
Marmion, pasó a la ciudad de Brujas desde Amberes en 1494, el año de la muerte de Memling, sin duda por la nuevas posibilidades de trabajo que se abrían a otros pintores. Aunque las obras de Provost hasta 1510 -recogidas por Friendlander en el tomo IX b de su Early Netherlandish Painting - muestran alguna semejanza con las de Picardo, particularmente en los modelos que utiliza para sus figuras, éstas muestran un canon más corto que el del burgalés y son mucho más rudas. Más cerca que de Jan Provost está León Picardo del estilo del autor de La Lamentación y Cristo en la cruz que se conserva en el Museo de la Iglesia del Salvador de Brujas, que Friendländer cataloga como obra brujense en torno a $1500^{32}$. En ellas se detectan tipos humanos similares a los del pintor picardo, particularmente en lo que afecta a los rostros, de canon corto y boca con tendencia hacia abajo. Más puntos en común que con los dos anteriores tiene León Picardo con Gerard David, particularmente con las obras realizadas por éste desde 1498 en que hizo El Juicio de Cambises hasta 1509. Prueba de ello es que en las dos tablas de San Bartolomé que representan exorcismos (figs. 6-7) muestra Picardo una composición que se aproxima a la de la historia de Cambises, tanto por el amplio número de personajes como por su marcada isocefalia. Y también se acerca en la forma en que dispone las figuras, situando a los extremos algunas con el rostro de perfil y disponiendo en un plano más retrasado otras de tres cuartos llenando los huecos, muy amontonadas. Junto a esto, algunos de los tipos que Picardo emplea para los rostros de determinados personajes, no se alejan demasiado de algunos de los de David, aunque existan variaciones en la forma en que cada uno los estructura. Particularmente significativos son algunos próximos al dibujo con el rostro de un hombre atribuido a Gerard David que se conserva en el Louvre ${ }^{33}$, representado con sombrero plano, de tres cuartos y barbado, mirando hacia la izquierda, si bien en Picardo el canon del rostro es algo más corto y el modelado más intenso. Y lo mismo se podría decir de los rostros femenimos, que pertenecen a esa misma tradición, con amplia frente, nariz alargada y mentón menudo. Más próximo si cabe a David es el modo en que Picardo traduce a San Bartolomé en la escena que transcurre en el templo de Astaroth (fig. 6), en la que el apóstol muestra una disposición muy parecida a la de Cristo de pie de Gerard David que se conserva en Dublín ${ }^{34}$, tanto en su actitud como sobre todo en la postura de los pies, e inclusive también en la de las manos, si bien en la tabla de San Lesmes, San Bartolomé tiene que variar una de ellas para sujetar su manto. Además de lo ya señalado, León Picardo coincide con Gerard David en la monumentalidad, en el carácter erguido que presentan en ocasiones sus figuras, aunque nunca sean así todas las que integran conjunto de la composición. Pero, si lo anterior resulta significativo, en nuestra opinión, lo es mucho más el modo en que dispone los plegados de las telas, modelados como rígidos bloques plásticos, ya sean rectos o se rompan en el suelo de forma más o menos irregular. Esto último también se puede comprobar en las obras de David de este período, como es el caso de la Magdalena de los desposorios de Santa Catalina de la National Gallery de Londres, realizada en torno a 1505 para Richard de Visch van Capelle, cantor de San Donato de Brujas, aunque en esa fase Gerard David mostraba ya habitualmente un modelado menos rígido, con un claroscuro que anima las superficies, algo que no se detecta en Picardo, cuyo modelado sigue siendo mucho mas rígido.

Pese a los puntos de contacto que el estilo de León Picardo en 1515 pueda tener con el arte brujense y en último término con Gerard David, no creemos, en ningún caso, que se deba a que haya habido una vinculación directa de Picardo con el taller de este último. A ello apunta, sin duda, el que, junto a notas comunes, existan notables diferencias entre el estilo del pintor brujense y el que el burgalés muestra en las tablas de San Lesmes, prescindiendo de la calidad objetiva

\footnotetext{
32 Early Netherlandish Painting, IX b, lám. 187, núm. 184.

33 Ib., VI b, lam. 228, núm. B.

34 Idem, lám. 204, núm. 198.
} 
de cada uno. Lo que más los separa, sin duda, es el modo en que Picardo traduce las arquitecturas y el paisaje, es decir, el escenario de unas composiciones integradas por personajes cuyos rostros y actitudes podrían recordar las del brujense. Ignoramos, si, además de esa hipotética relación con Brujas que hemos sugerido para León Picardo, éste pudo haber estado en contacto con la pintura de otras ciudades flamencas como Amberes, donde destacaba Quintín Massys, influido por el Renacimiento, o inclusive Bruselas. Probablemente, de haber estado Picardo en alguna de ellas -lo que por el momento tampoco se puede asegurar-, su estilo podría haberse transformado incorporando en sus arquitecturas una dependencia mayor del arte italiano de la que muestran sus obras en 1515. A juzgar por ellas, el conocimiento que tenía por esas fechas de ese arte no debía ser grande. Por esta razón, quiza no sería descabellado pensar que pudo haber accedido a él en Burgos, junto a Bigarny, ya que, como el mismo Picardo confiesa a Tampeso -Sagredo- en las Medidas del Romano, no había estado en Italia.

De lo dicho hasta ahora se deduce que, si bien algunas notas del estilo de León Picardo le vinculan de algún modo a Brujas, y en particular a Gerard David, en él hay también ecos de su primera formación - probablemente en su región natal- . Sin duda, debido a ello, Picardo muestra esos rasgos singulares que permiten distinguir su personalidad de la de otros pintores con los que tiene algún punto en común. Indiscutiblemente, como siempre, lo más significativo son los tipos humanos que selecciona, y en particular algunos de los masculinos que repite sistemáticamente, al igual que hace con alguno de los femeninos. En los primeros lo que más llama la atención es el canon corto y ancho de sus rostros y su preferencia por mostrar los cabellos, hechos con pincel fino, cayendo sobre la frente en rizos desordenados e irregulares, visibles aunque los dote de tocados que ocultan parcialmente sus frentes. Junto a esto resulta también peculiar el que alguna de sus figuras masculinas -indiscutiblemente las más personales- muestren el ceño fruncido y los ojos excavados profundamente bajo las cejas, mirando hacia arriba. Su posición de tres cuartos deja ver una nariz larga con tendencia hacia abajo, a escasa distancia de la boca, que se cierra formando un rictus, asimismo hacia abajo, en un gesto que repite frecuentemente. Se puede comprobar en la escena en que San Bartolomé está en el templo de Astaroth (fig. 6) en el personaje que se encuentra al lado del apóstol ricamente vestido o en los dos que aparecen tocados con turbantes, en el último plano, a la derecha. Además de los que muestran ese gesto característico en la boca, hay otros que tienen los labios bien dibujados, con el inferior más pequeño y ancho que el superior, como se puede verificar en la figura de San Bartolomé en las dos tablas en las que realiza exorcismos (figs. 6 y 7). Igualmente definitorias son las figuras femeninas, que, con frecuencia, se representan, o vestidas a la moda y, en ese caso, ostentan ricos tocados de origen nórdico, o con manto o tocas cubriéndoles los cabellos. A diferencia de las masculinas, sus rostros presentan un canon mucho más alargado, con la frente curvada y el nacimiento del pelo hacia atras. Este, si es visible bajo los tocados, muestra ondulaciones y se hace también con pincel fino. Además de lo ya dicho, sin duda lo que más destaca en los rostros femeninos de Picardo es lo alargado de su nariz y, sobre todo, su mentón menudo y afilado a escasa distancia de la boca.

Otros rasgos definen también a las figuras que Picardo incluye en sus obras. Entre ellos destaca tanto la forma de sus manos, de largos dedos que muestran la estructura ósea, al igual que hace con los rostros de los personajes masculinos que presentan un acusado modelado, como los gestos de que las dota, con su carácter forzado y artificioso tan personal, muy similar al de Gerard David. Y no menos singular resulta otro que se cuenta entre sus notas más características, el modo en que traduce las telas y, en particular, la forma que adoptan sus plegados. Ya nos hemos referido antes a cómo reproduce algunos de ellos, como bloques rígidos, casi esculpidos. Sin duda, en una de las escenas donde mejor se puede comprobar esto, es en la de la sustitución de San Bartolomé recién nacido por un demonio (fig. 4). En el dosel bajo el que duerme la madre 
del santo se pueden ver algunos rectos paralelos al fondo y otros que rompen de forma artificial sobre la cama, como artificiales son los otros más pequeños que forman los vestidos de las dos figuras femeninas sentadas junto al lecho o mucho más grandes en la falda de la hija del rey (fig. 7) en la escena en que San Bartolomé la exorcisa, o en la propia capa del apóstol que llega hasta el suelo en esa misma tabla. Junto a los ya citados, aparecen otros, más nerviosos y revueltos, similares a los que realiza Gossaert, aun cuando no sean tan marcados ni tan abundantes. Estos últimos se pueden ver en la escena en que el sacerdote encuentra a San Bartolomé recién nacido en el monte (fig. 5) en el personaje que aparece de pie, a la izquierda. Además de éstos, se deben destacar asimismo otros que se van a encontrar más tarde en las obras que le atribuimos a él y a su taller, formados por unas lineas curvas paralelas, muy largas y muy juntas, como el manto que lleva el apóstol al fondo a la derecha en la tabla del exorcismo de la hija del rey, en la escena secundaria en la que Bartolomé se aparece al monarca al día siguiente del milagro (fig. 7).

Sin duda otro de los aspectos más personales del estilo de Picardo es el modo en que reproduce los edificios que constituyen el marco de muchas de sus escenas. Teniendo en cuenta que conoció el arte renacentista por vía indirecta, ya que, como él mismo nos dice, en 1526 aún no había estado en Italia, es muy posible que haya accedido a él a raíz de su llegada a España en 1509, aunque tampoco puede descartarse el que lo hiciera antes de venir, según se indicó antes. Pero, en cualquier caso, lo cierto es que lo único que parece haber manejado son algunos motivos del repertorio decorativo renacentista, los más simples y repetidos, que bien podría haber asimilado gracias a su colaboración con Bigarny. Éstos se incorporan en unos edificios construidos con soportes de sección cuadrada, con frecuencia cajeados, con capiteles con motivos de acanto y el ábaco en forma cóncava -algo que repite con insistencia- . Además de lo ya indicado, quizá lo más reseñable sea su gusto por las superficies lisas y las líneas rectas horizontales y verticales. Con ellas forma molduras, frisos, cajea los soportes o estructura los paramentos. Y también resulta muy peculiar la incorporación de los que podrían ser grandes dentellones, utilizados de forma que implica un desconocimiento de su función en el entablamento clásico, y que aparecen después en otras obras que adscribimos a su taller. Se pueden comprobar en la escena del exorcismo de la hija del rey (fig. 7), a la izquierda, en el edificio que forma parte del escenario urbano, y también los incluye a la derecha de la escena del templo de Astaroth (fig. 6). Dignas de destacar en esta última son sin duda las hornacinas para las estatuas desnudas, y en particular el modo en que sitúa en el centro la del dios sobre un alto pedestal, encima del que dispone una rica muestra de su repertorio renacentista, como también lo es la cubierta avenerada, tan frecuente en las hornacinas de los retablos salidos del taller de Bigarny. La forma en que diseña la estatua que se quiebra como consecuencia del milagro del santo, su actitud compleja y, sobre todo, el modelo que utiliza para su rostro y los cabellos cortos con mechones desordenados nos proporcionan un tipo humano que luego aparece en las obras que se han adscrito al maestro llamado de Támara, cuya vinculación con el estilo de León Picardo se abordará después.

Las tablas de la historia de San Bartolomé conservadas en la iglesia de San Lesmes de Burgos, y en particular la del sacerdote encontrando al apóstol recién nacido en el monte (fig. 5), permiten verificar el modo en que Picardo representa el paisaje, muy diferente también al de Gerard David. Sin duda lo más significativo son los árboles, que, en lugar de mostrar una tendencia vertical como los del pintor de Brujas, se inclinan movidos por el viento y presentan una forma irregular, al igual que las nubes que se alzan sobre el fondo o las rocas, cuyo tono más cálido contrasta con el color frio verdoso del fondo en el que se funden las montañas y las nubes. Y esto mismo se puede constatar en la tabla del exorcismo de la hija del rey (fig. 7) en la escena secundaria visible a traves de la puerta abierta al fondo, con el santo rechazando las riquezas que se le ofrecen.

Otra de las notas que se deben reseñar en las tablas de San Lesmes es su colorido brillante, 
con amplio dominio de rojos y verdes muy vivos, sin la abundancia de azules que caracteriza a otros pintores de la zona. Posiblemente porque se lo exigen los comitentes $-\mathrm{o}$ inclusive de acuerdo con sus preferencias personales- sus personajes se visten con trajes de brocado que se simula aquí con amarillo, o lucen ricas joyas o piedras preciosas, como se puede comprobar en el manto de San Bartolomé, aspecto este entre otros muchos que separa el estilo de León Picardo del de Jan Joest de Calcar con el que le había asociado Post en 1942, según se indicó antes.

Pese a que la indumentaria que lucen sus figuras responde a la moda nórdica, no faltan tampoco algunos huellas que denotan la influencia de lo hispano en ellas, como el típico trenzado que recoge los cabellos de la joven que se encuentra en primer plano, a la izquierda de la escena en que el demonio rapta a San Bartolomé recién nacido (fig. 4), o la abundancia de turbantes. Su presencia constituye un claro testimonio de que Picardo se "hispaniza", acoge en sus obra elementos que reflejan la huella del nuevo ambiente en el que transcurre su vida, al igual que le sucedió a Juan de Flandes, sobre todo en su etapa palentina.

\section{Otras obras que se pueden atribuir a León Picardo o a su taller}

Las características que muestran las tablas de San Bartolomé que se guardan en la iglesia de San Lesmes, obra documentada del pintor picardo, constituyen el punto de partida para adscribir otras obras tanto a él como a su taller. Sin duda la más próxima al estilo de León Picardo de todas las pinturas castellanas que se conocen de esos años es una tabla que perteneció a la colección Albarrán de Madrid y que actualmente se encuentra en el Museo de Burgos $(1,20 \times 1,13)$. Díaz Padrón y Padrón Mérida la reprodujeron por primera vez en $1983^{35}$, señalando su advocación, El Bautismo de San Agustín y su hijo Adeodato por San Ambrosio en presencia de Santa Mónica (fig. 8), con una escena secundaria -tan del gusto de Picardo-, a la derecha, con San Ambrosio tentado por el demonio. En aquella ocasión, los dos autores se hicieron eco de la atribución dada por Angulo en 1945 -retomada después por él en 1954- al mismo autor que hizo El Calvario de la Diputación de Logroño y unas tablas que entonces estaban ya en Barcelona. Angulo se preguntaba en 1945 qué relación podía guardar con la escuela burgalesa un maestro que trabajaba en Logroño ${ }^{36}$. Entonces no sabía que el retablo procedía de Támara en Palencia, pero cúando se enteró en $1954{ }^{37}$, no sólo aumentó el número de sus atribuciones, sino que vinculó a este maestro con la pintura palentina. Tanto es así que después de él se denonimó a este pintor Maestro de Támara, a partir de del retablo que hizo para esta iglesia, disperso en la actualidad.

Aunque existen muchas coincidencias entre la tabla del Bautismo de San Agustín (fig.8) y las que se atribuyen al llamado Maestro de Támara, sobre cuya relación con León Picardo se discutirá al final, lo cierto es que, una vez conocido el verdadero estilo de Picardo, no hay duda de que se debe a la mano de este último. Su calidad y su cuidado técnico, sin recurrir al oro para traducir los brocados como en las tablas de la iglesia de San Lesmes, así como las características que muestra, sugieren que Picardo debió realizarla poco tiempo después de hacer las de San Bartolomé. Buena prueba de ello es que se pueden comprobar en la tabla del bautismo de San

\footnotetext{
35 «Miscelánea de pintura española", Archivo Español de Arte, 1983, núm. 223, pp. 196-198.

36 Art. cit. 1945, pp. 95-96. La Rioja se encontraba entonces en el radio de acción del foco burgalés; de ahí que algunas de sus obras más destacadas correspondan a artistas establecidos en Burgos, al igual que sucedió en el hispanoflamenco. Sobre este punto, véase P. Silva Maroto, ob. cit., 1990.

37 Angulo fñiguez, Pintura española del siglo XVI, "Ars Hispaniae», XII, 1954, pp. 105-106. Con Palencia sucedía lo mismo que se ha señalado respecto a Logroño en la nota anterior, si bien en ella, en el primer tercio del Xvi, la situación iba cambiando.
} 

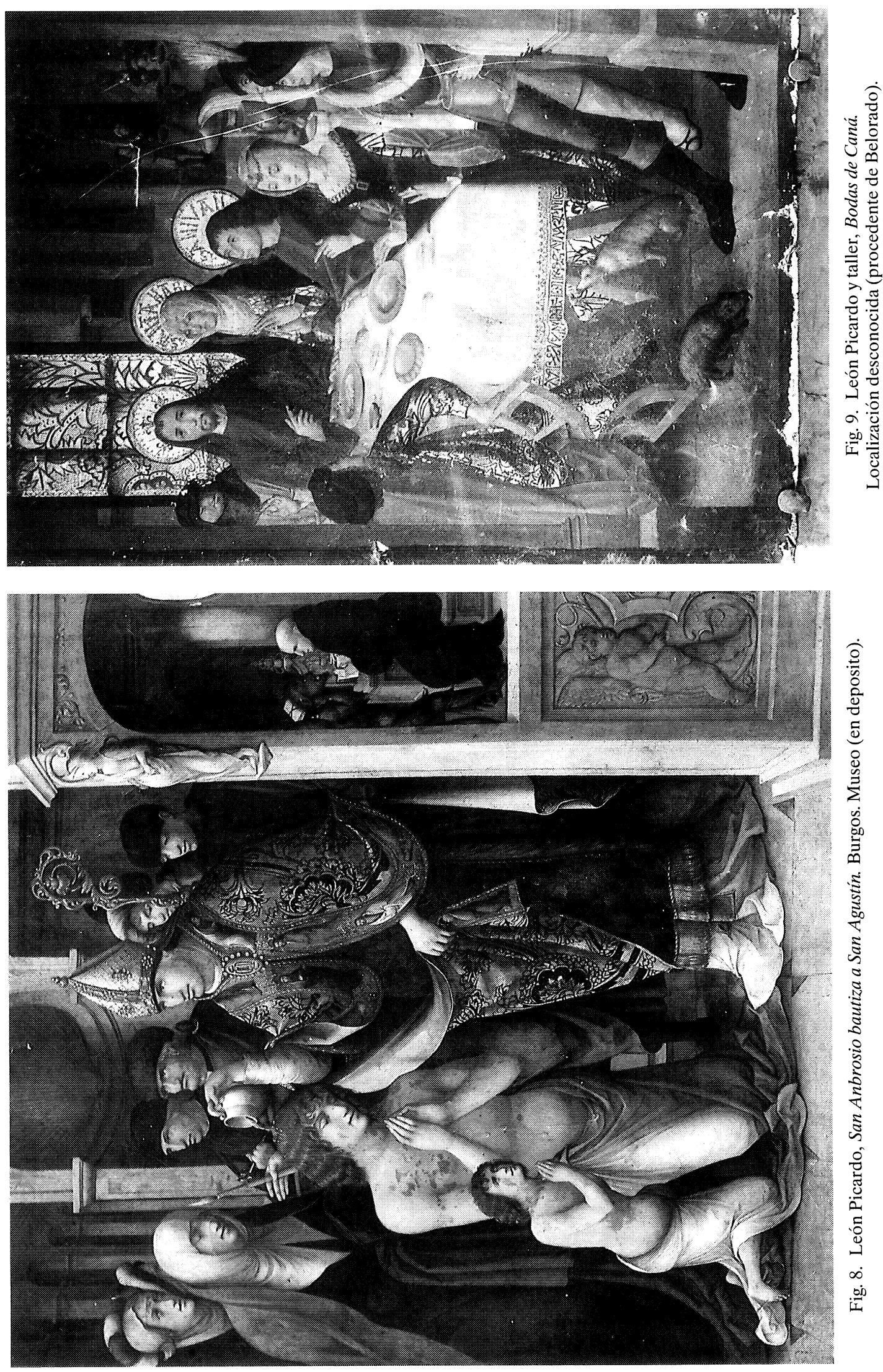

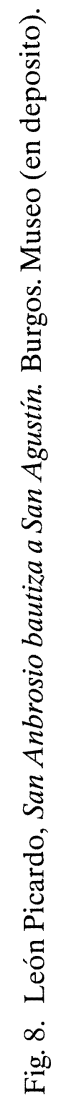


Agustín los mismos tipos humanos, dispuestos de forma similar, con su habitual isocefalia, menos evidente aquí por la tiara de San Ambrosio que sobresale del resto de las cabezas, en las que se identifican los mismos modelos empleados en San Lesmes para los rostros. De los masculinos cabe destacar entre los que aparecen en segundo plano los de cánon corto, con su típica mirada hacia arriba y sus labios apretados formando un rictus hacia abajo. Igualmente característicos son los cabellos de San Agustín, con sus rizos irregulares cayendo sobre la frente, tan peculiares. Y no lo son menos los femeninos, tanto la joven con su rico tocado a la moda, como Santa Mónica, por no mencionar la forma de los plegados tan singular. Se puede comprobar en los que forman en el suelo los vestidos de los dos bautizados de rodillas, pequeños e irregulares, o los verticales, rígidos como bloques del manto de Santa Mónica. Además de lo ya dicho, coinciden también la forma y los gestos de las manos y el modo en que traduce el edificio eclesial en que transcurre el bautismo. Respecto a esto último, sólo indicar que, junto a su habitual dominio de línea rectas y soportes de sección cuadrada con los típicos cajeados, se puede detectar aquí una mayor riqueza decorativa, particularmente a la derecha de la tabla en el putti del friso o en la escultura femenina, que tal vez responden al manejo de grabados por parte del pintor o accedió a ellos por cualquier otra vía.

Además del Bautismo de San Agustín, se puede vincular con el estilo de Picardo la tabla de Las bodas de Caná de la iglesia de Belorado (fig. 9). Ésta, junto con la del Nacimiento de Cristo del mismo conjunto, que se debe a una mano distinta a la anterior, le sirvió a Post en 1947 como base para la reconstrucción de un maestro que trabajó en el primer tercio del XVI en la zona al que denominó «de Belorado " a partir de ellas ${ }^{38}$. Pese a que ninguna de las dos se encuentra ya en Belorado y no se conocen más que a traves de fotografías antiguas en blanco y negro, al analizar las características que presenta la de las bodas de Caná, se percibe claramente que se trata de una obra vinculada al estilo de León Picardo. Su calidad, menor que la de las tablas de San Lesmes y el bautismo de San Agustín, sugiere que, para ejecutarla, Picardo debió recurrir a la colaboración de su taller. Aunque, a juzgar por la indumentaria que lucen sus personajes vestidos a la moda, debe situarse antes de 1520 , presenta ya un alto grado de «hispanización» que se detecta también en la amplia presencia del oro, en nimbos y brocados, tan del gusto de los comitentes antes de esa fecha.

Sin problema podemos reconocer en la tabla de las bodas de Caná (fig. 9) los mismos tipos humanos utilizados por Picardo en las historias de San Bartolomé. A ellos remiten sin duda el rostro de Cristo o el de San Juan, con los típicos mechones cayendo irregularmente sobre la frente o los de los coperos a la derecha, que miran hacia arriba con sus rostros dispuestos de tres cuartos. Y qué decir del que se sienta junto a Cristo mirando hacia abajo, con el cánon del rostro cortísimo y la nariz larga empotrada en la boca y la forma que muestra ésta. Lo mismo que sucede con los masculinos, también María y la novia podrían encontrar paralelos entre las mujeres que reproduce Picardo en las tablas de San Lesmes. De las dos, la más significativa es la novia, al igual que su traje y su rico tocado a la moda. También se reconocen en ella los mismos gestos de las manos y el mismo tipo de plegados, como los que muestra el novio, de espaldas a la izquierda o el manto de San Juan y, sobre todo, la banda que luce el copero de la derecha, con esos largos plegados hechos con curvas paralelas y muy juntas. Otros puntos comunes son asimismo el modo en que traduce el asiento en el que descansa el novio, tratado de forma similar a la tapa del

38 A History of Spanish Painting, IX, p. 593. Al escribir en 1933 el vol, IV (pp. 308-311, fig. 118) relativo al hispanoflamenco castellano, asoció estas tablas a la predela del Espino, que nada tiene que ver con ellas, ya que corresponde a un maestro llamado de Villalonquéjar. Sobre éste véase Pilar Silva Maroto, ob. cit. 1990, II, pp. 494-497. La figura del Maestro de Belorado está exigiendo una revisión. En 1984 Pilar Silva Maroto se refirió a su derivación del Maestro de los Balbases en "Notas para un mejor conocimiento de la pintura burgalesa de fines del siglo xv y el primer tercio del xvI" en $L a$ ciudad de Burgos, Actas del Congreso de Historia de Burgos, 1984, pp. 888-889. 
brasero, hecha también de madera, de la escena del rapto de San Bartolomé recién nacido (fig. 4), la presencia de animales como en ellas, o el marco arquitectónico en que dominan las líneas rectas. Ante él vemos al fondo, a la derecha, un pasaje secundario de esta escena, con los criados llenando sus jarros de vino, igual que se hacía en el retablo de San Bartolomé.

También se identifica el estilo de Picardo con la colaboración de su taller en dos tablas con la historia de Santa Catalina de la iglesia de Santibañez Zarzaguda ${ }^{39}$, La disputa de la santa con los filósofos (fig. 10) y el martirio de las ruedas, que debió ejecutarse en una fecha similar a la de Belorado, ya que, como en ella, se incorporan tapices de brocado realizados con oro, al igual que los nimbos. Como en la tabla de las bodas de Caná (fig. 9), también en éstas se detectan los tipos repetidos por Picardo, particularmente en el filósofo sentado a la derecha de la santa en la disputa o los dos situados al fondo tras la ventana en esa misma tabla. Idénticos son asimismo los plegados en las dos escenas, si bien difiere algo el marco arquitectónico de la disputa, con una decoración mucho más rica como en el Bautismo de San Agustín, pero, aún así, con el mismo dominio de líneas rectas y soportes cajeados de sección cuadrada que caracteriza toda su producción. Por lo que respecta al martirio de la santa, éste transcurre ante un fondo de paisaje con nubes, que no dista demasiado a las que se pueden ver en el retablo de San Bartolomé.

Caracerísticas similares a las de las dos obras anteriores se pueden comprobar en algunas de las tablas que componen el retablo dedicado a los dos santos Juanes que se hizo para la iglesia palentina de Herrera de Valdecañas y en la actualidad se encuentra en el Museo Diocesano de Palencia. Post en $1947^{40}$ lo adscribió al Maestro de Belorado, sin duda porque vio en él notas similares a las de las dos tablas de la iglesia de Belorado, citadas antes, mientras que Angulo en 1954 consideraba probable su adscripción al grupo de obras que otorgaba al que después habría de llamarse Maestro de Támara ${ }^{41}$. Como en Belorado, también en Herrera de Valdecañas se produjo una colaboración entre dos talleres ${ }^{42}$, los mismos en ambos casos, el de Picardo y el del maestro llamado de Belorado. Este hecho resulta bastante habitual, e incluso respecto a Picardo se conserva un testimonio documental, correspondiente a esos años, el retablo de Santa Dorotea que Picardo y Orozco hicieron a partir de 1516 por encargo de los herederos del obispo de Almería, don Juan de Ortega ${ }^{43}$. Teniendo en cuenta la fecha en que esto sucede, no sería extraño que algún día se pudiera identificar al de Belorado con Juan de Orozco, ya que coincide con los años en que el taller de Picardo colabora con el del Maestro de Belorado.

$\mathrm{Al}$ analizar las tablas que componen el retablo de Herrera de Valdecañas se constata que el taller de Picardo intervino en la ejecución de los profetas de la predela-Jacob, Abacuc (fig. 11), Jeremías (fig. 12), Daniel, Isaur y Zacarías ${ }^{44}$ - . Del cuerpo del retablo sólo se hizo cargo de dos de las historias del Bautista, la escena de la predicación del santo (fig. 13) y la de La degollación (fig.14). Las características que muestran todas ellas, con una técnica menos cuidada y de menor calidad incluso que las de Belorado, nos inclinan a pensar que se trata de una obra salida del taller de Picardo sin su participación, lo que se justifica sin duda por el carácter local del encargo,

39 Post, IX, pp. 661 . Al estudiar al Maestro de Argaño se refiere a estas dos tablas señalando su proximidad a las escenas narrativas del retablo de Buezo (Burgos), con las que nada tienen que ver, como tampoco con el Maestro de Argaño ni con el de Sinobas al que vincula finalmente las de Buezo.

40 Post, IX, p. 600.

41 Ob. cit., 1954, pp. 105-106.

42 Se aludió ya a ello en Mateo y Silva, "Nuevas tablas burgalesas de fines del xv y comienzos del xvi en colecciones artísticas madrileñas", Archivo Español de Arte, 1987, p. 207, figs. 10-12. Sobre este retablo véanse también Ángel Sancho Campo, El Museo Diocesano de Palencia, V, 1978, p. 34, figs. 37-41, y Ramón Revilla Vielva, Catálogo Monumental de la provincia de Palencia, vol. I, partidos de Astudillo y Baltanás. 2. ed. rev. 1951, p. 68, figs. 108-112.

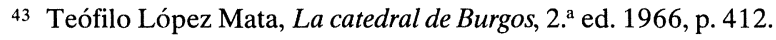

44 Los dos últimos, de menor calidad, sin duda se deben a la colaboración de un miembro distinto del taller al que intervino en las restantes tablas que le adscribimos de este retablo. Sobre ellas véase también el artículo citado en la nota 42. 


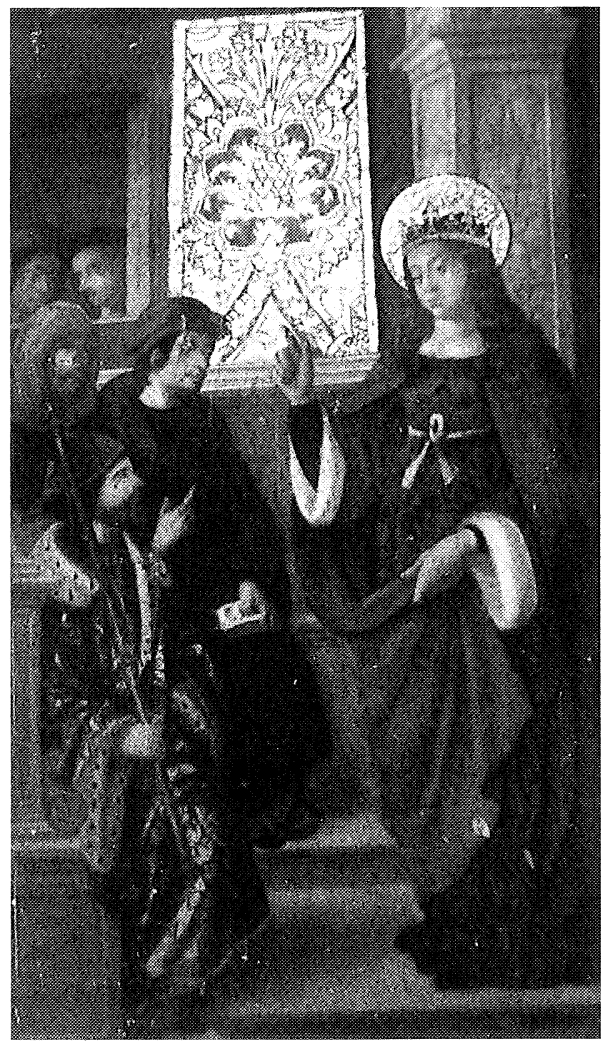

10

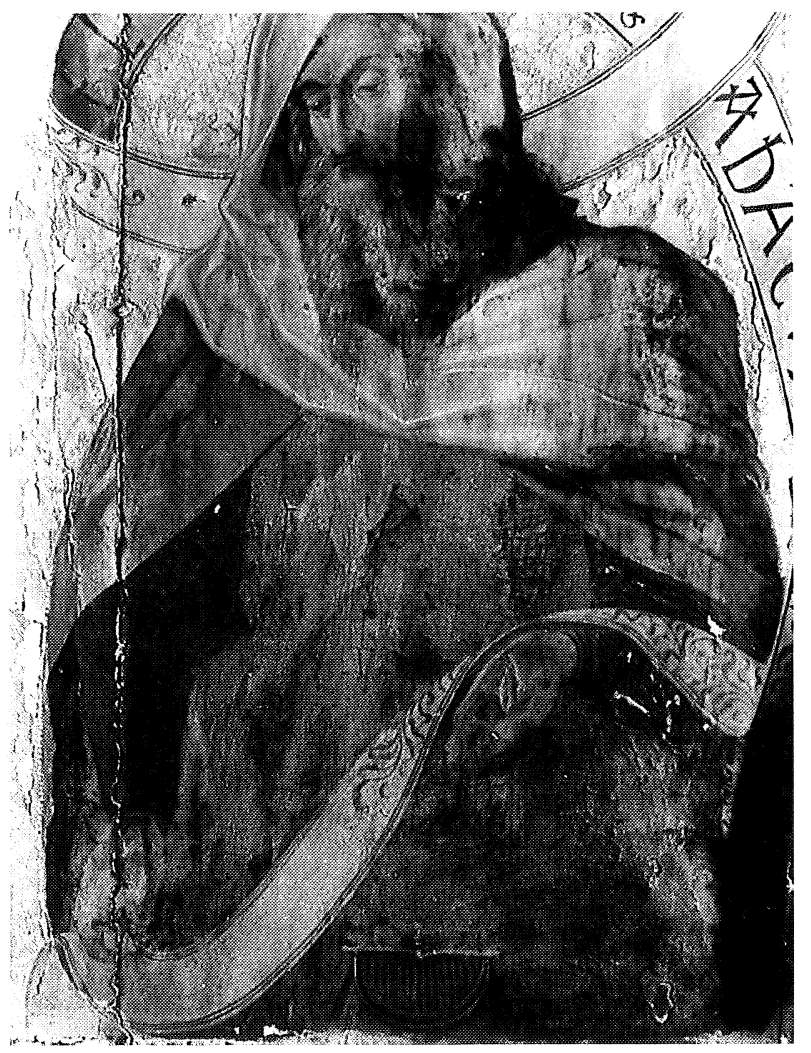

11

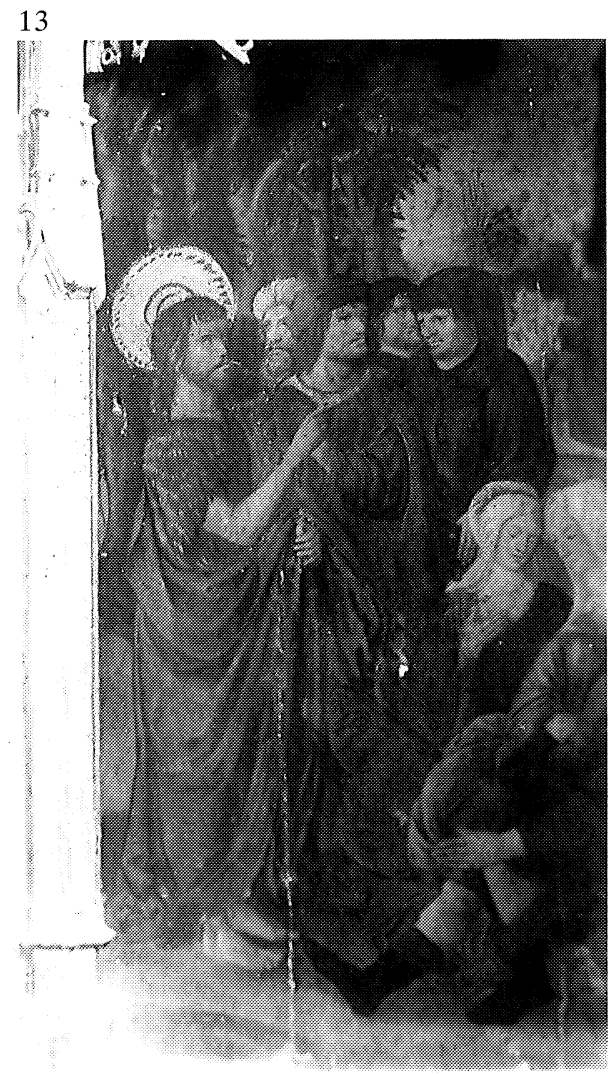

12

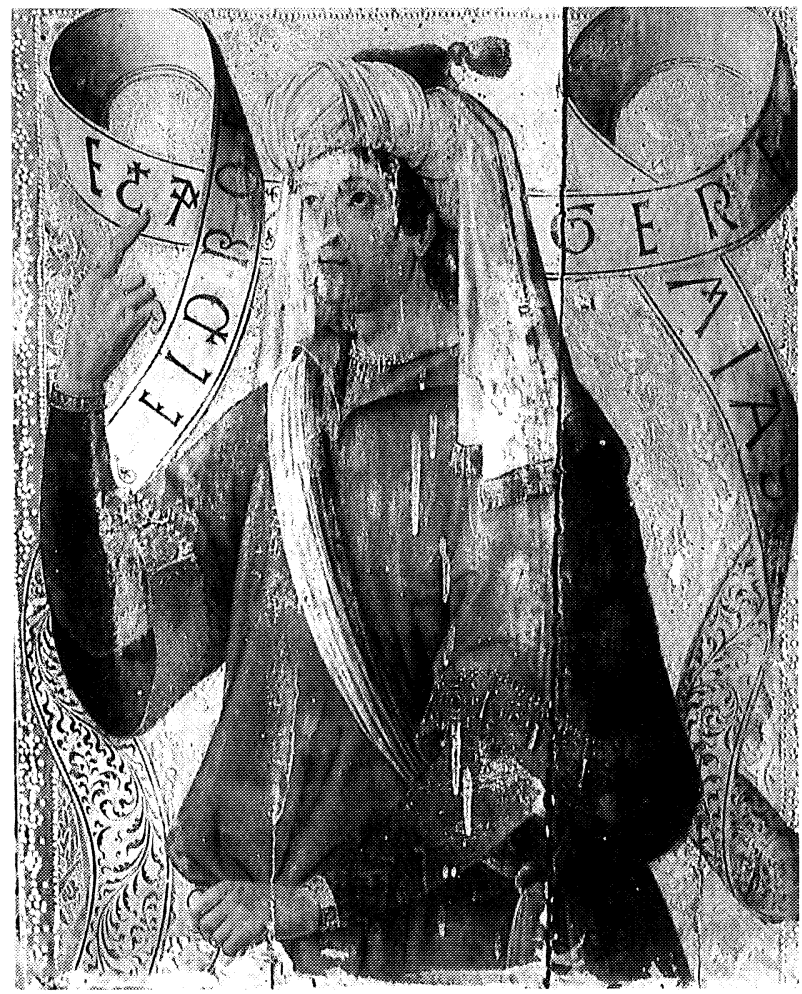

Fig. 10. León Picardo y taller, Disputa de Santa Catalina con los filósofos. Santibánez Zarzaguda (Burgos) Iglesia. Fgs. 11, 12 y 13. León Picardo y taller, Abacuc, Jeremias y Predicación del Bautista. Museo Diocesano de Palencia (antes Herrera de Valdecañas) 
con una traza aún al «moderno», aunque como mínimo se debió hacer a partir de 1520 . No obstante, pese a ello, se pueden encontrar en las distintas tablas que correspondieron al taller de Picardo unas notas similares a las que aparecen en las tablas de San Bartolomé y en las restantes que hemos atribuido a este pintor o a su taller. Particularmente significativa es la escena de $\mathrm{La}$ predicación del Bautista (fig. 13). El precursor casi repite la figura de San Bartolomé en la escena del templo de Astaroth (fig. 6), como se percibe tanto en los plegados del manto como en su actitud. Sin embargo su rostro no sigue el mismo modelo que el del apóstol, sino el del personaje que se encuentra a su lado, con los típicos ojos mirando hacia arriba y los labios apretados en un rictus hacia abajo. Y si coinciden algunas figuras -incluidas las femeninas con los tocados a la moda que aquí están sentadas en el suelo-, también lo hace la composición, con los personajes que dispone en distintos planos llenando los huecos y la marcada isocefalia que le caracteriza. Por si eso no bastara, también el paisaje responde al mismo patrón, con esos árboles irregulares tan personales, aunque, eso sí, traducidos sin la precisión y el cuidado que tenían los de la escena del sacerdote encontrando a San Bartolomé recién nacido en el monte (fig. 5). Esa falta de cuidado se percibe igualmente en los árboles que aparecen al fondo del patio del palacio de Herodes en La decapitación del Bautista (fig. 14). En esta última escena, no sólo coinciden los tipos humanos empleados, como se comprueba en la cabeza cortada de San Juan, sino también en las de Herodías y su acompañante. Respecto a ésta, resulta no menos significativo que su rostro, la toca con esos típicos plegados curvos, paralelos y muy juntos que aparecen en la mayor parte de sus obras. Y qué decir de la arquitectura, con sus paredes lisas, estructuradas sólo con líneas rectas sin decoración, al igual que los capiteles con sus habituales ábacos cóncavos, y esta vez sobre columnas, por no citar esa especie de dentellones tan personales que se divisan tras el muro del patio. Al igual que las dos historias del Bautista, también los profetas muestran sus tipos humanos preferidos, particularmente Abacuc (fig. 11) y Daniel, sin mencionar a Jeremias (fig. 12), que exhibe una banda con sus típicos plegados curvos paralelos.

Para concluir, queda ya sólo señalar la relación que León Picardo tiene con el llamado Maestro de Támara, a quien hemos aludido antes. Angulo en 1954 se refirió a ello, si bien entonces no sospechaba que las tablas de San Lesmes fueran de León Picardo. Con su reconocida intuición y «buen ojo», indicaba ya que, aunque la relación estilística de este pintor -al que entonces conectó con Palencia- "con la serie de las tablas de San Lesmes de Burgos en varios aspectos, no llego a convencerme de que pueden ser la misma persona. Más flamenco el autor de la serie de San Lesmes, no sé si pudiera buscarse en él al maestro del anónimo de Támara» ${ }^{45}$. Pese a que no hay dudas de que existe una gran relación entre las dos series, las que hemos adscrito a León Picardo a partir de las tablas de San Lesmes ${ }^{46}$, muestran unas características que se adecuan a un artista que, como Picardo, había concluido su formación en 1509. En cambio, las otras, las que integran la serie de Támara, a partir de los restos de este retablo palentino ahora disperso ${ }^{47}$ y de La Crucifixión de la Diputación de Logroño que constituyen las bases para la reconstrucción de su estilo, denotan un estadio más avanzado, probablemente a partir de 1525 , si bien, en cualquier caso, derivado del anterior. Lo que en ellas se manifiesta que las distingue de

\footnotetext{
45 Angulo, ob. cit., 1954, pp. 105-107.

46 Entre las que coinciden con las que atribuimos a León Picardo, se cuentan la tabla del Bautismo de San Agustín de la colección Albarrán y las tablas de Herrera de Valdecañas, aunque sin distinguir entre los dos talleres que colaboraron en su ejecución.

47 Varias se conservan en la colección Godia de Barcelona y las recoge Luis Monreal Agustí en El Conventet. Colección de pintura antigua, 1978, pp. 102 y ss., cat. 34-37. Reproduce La Asunción de la Virgen, La Adoración de los Magos, San Juan Evangelista y San Lucas, incluyendo también imágenes de sus reflectografías infrarrojas, que permiten conocer su peculiar grafía, particularmente esas líneas curvas largas y paralelas, muy juntas que vemos en el rostro y el cuello de San Juan, no muy alejadas de las que se traslucen en superficie en el dosel de la escena del demonio raptando a San Bartolomé recién nacido de San Lesmes (fig. 4).
} 

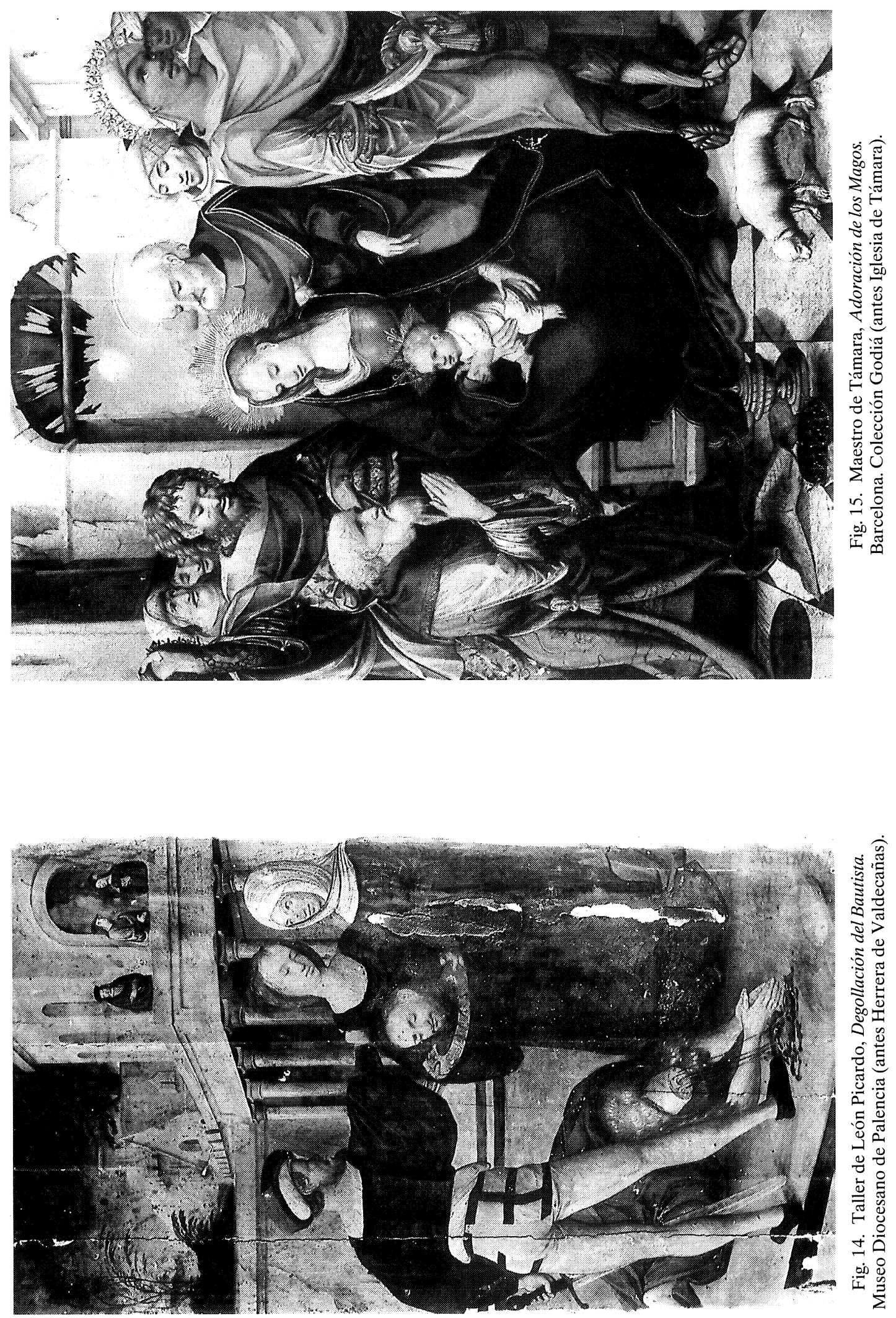
las tablas de San Lesmes es un interés por el movimiento, por la expresión, que nos descubre un temperamento más dramático, más intenso de lo que se podría esperar del autor de la primera serie.

Pese a que no se puede dudar de la conexión y aun dependencia estilística entre las dos, no es fácil llegar a una conclusión. Tomando como ejemplo una de las escenas del retablo de Támara, la de la Coronación de espinas, se comprueba que los tipos humanos son similares, particularmemte en los rostros masculinos de canon corto, con los ojos mirando hacia arriba y la boca apretada con ese rictus hacia abajo tan peculiar, al igual que los cabellos con sus típicos mechones irregulares sobre la frente, ahora mucho más revueltos, como se puede ver en el tercero de los Reyes en La Adoración de los Magos de ese conjunto de la colección Godia de Barcelona (fig. 15) ${ }^{48}$. Y también son similares las arquitecturas, con su dominio de líneas rectas y sus soportes de sección cuadrada cajeados como en Picardo, al igual que el paisaje. Este se puede analizar en $E l$ Calvario de Logroño, reproducido por Angulo en el «Ars Hispaniae», y constatar las nubes aparatosas, los árboles inclinados por el viento que los agita como en las tablas de San Lesmes.

Junto a esas notas comunes -que precisamente son las que se mantienen más tiempo en los artistas de este momento-, esto es, los tipos que usa para sus personajes, el marco arquitectónico y el paisaje, existen tambien variaciones. Las más significativas son las que afectan a la posición y la actitud que muestran las figuras. Ya no hay ninguna erguida como en las del retablo de San Lesmes. La monumentalidad que pusiera en conexión a este último con las de Gerard David ha desaparecido. En su lugar domina un movimiento que agita a las figuras. Sin duda lo que ayuda a ello, además de las poses complejas que adoptan, como se ve en El Calvario de Logroño, son también los movimientos de que dota a los trajes que las cubren que parecen como impulsados por el viento. Ante esto, no hay más que dos explicaciones: o bien se trata de las obras de dos maestros distintos, derivado uno -el de Támara- del otro, en cuyo taller se tuvo que formar, o de un único maestro, en ese caso León Picardo, en dos fases distintas de su actividad. Ante este dilema, y sin elementos de juicio suficientes, no se puede llegar a una conclusión definitiva, ya que tanto podría haber sucedido lo uno como lo otro. Lo único apuntar que, de tratarse de León Picardo, esa segunda fase -identificada ahora con la figura del Maestro de Támara- sería la respuesta dada por un pintor formado a principios de siglo para hacer frente a los gustos de una época tan avanzada como la que trabajó Picardo hasta su muerte en 1543. Y aunque esto es posible, por el momento, con los datos que tenemos, creemos que resulta más acertado considerar que son dos pintores, derivados uno del otro.

48 Ib., cat. 35 . 